CASE MARKING AND ISLANDHOOD IN EST: EVIDENCE FROM QUECHUA

Peter Cole and Gabriella Hermon

University of Illinois

I. Introduction

There are certain syntactic properties associated with sentences like (1) in English.

(1) Frank believes $\left\{\begin{array}{l}\text { Charles } \\ \text { him/*he }\end{array}\right.$ to be asleep.

Sentences like (1) differ from those like (2) in a number of ways.

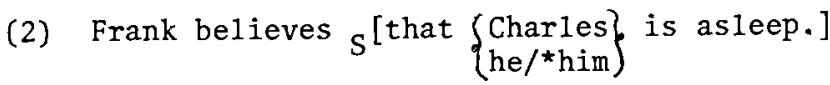

First, the underlying complement subject of (1) (Charles) is susceptible to a variety of syntactic rules, while that of (2) is not. Some examples of this difference are given in (3)-(6) .

(3) Passivization

a. Charles is believed by Frank to be asleep.

b. *Charles is believed by Frank that is asleep.

(4) Reciprocal Interpretation

a. Charles and Frank believe each other to be asleep.

b. *Charles and Frank believe that each other are asleep.

(5) Disjoint Reference

a. Charles ${ }_{i}$ believes $\left\{\begin{array}{c}{ }^{*} \text { him }_{i} \\ \text { him }_{i}\end{array}\right\}$ to be asleep.

b. Charles believes that $\mathrm{he}_{i, j}$ is asleep.

(6) Reflexive Interpretation

a. Charles believes himself to be asleep.

b. *Charles believes that himself is asleep.

Second, the complement clause in (1) is non-finite (untensed), while that in (2) is finite. Third, the underlying complement subject in (1) appears in accusative case, while that in (2) is in nominative case.

Within generative syntax there have been two widely accepted explanations proposed for the differences between (1) and (2). In the Standard Theory the properties of (1) have been analysed as due to the application of subject to object Raising (SOR). This rule is claimed to map an underlying structure like (7) onto a derived structure roughly like (8).

(7) $\left.\left.\mathrm{s}^{[\mathrm{NP}} \mathrm{V}_{1} \mathrm{~S} \mathrm{~s}_{2}^{\left[\mathrm{NP}_{2}\right.} \mathrm{VP}\right]\right]$

(8) $\mathrm{s}^{[\mathrm{NP}} \mathrm{V} \quad \mathrm{NP}_{2} \mathrm{~s}^{[\emptyset}$ to $\left.\left.\mathrm{VP}\right]\right]$

(C) Peter Cole and Gabriella Hermon 1979. 
The differences between (1) and (2) are claimed to be due to the fact that (1) has a derived structure like (8), while the derived structure of (2) is like (7). The rules in (3)-(6) are assumed to be clause bounded. Thus, they apply to the raised (accusative) NP, but not to the unraised (nominative) NP.

In contrast to the raising analysis, within the framework of the Extended Standard Theory (EST), it has been proposed that (1) has a structure like (7) in both underlying and derived structure. According to this approach, the differences between (1) and (2) are not due to the derived constituency of the complement subject (which is claimed to be the same in both sentences), but rather to differences in the internal structure of the complement clause. In the most recent version of EST, that proposed by Chomsky (1978) in "On Binding", the determining factor is the superficial case marking of the complement subject. More specifically, nominative NPs are, in effect, islands with respect to syntactic rules (the Nominative Island Condition [NIC]). It is the islandhood of nominative NPs that explains the distribution observed in (3)-(6).

The two approaches make radically different claims regarding the structure of complex sentences and the conditions on rule application. How might the approaches be distinguished? One possibility is to look at the implications of the two analyses for other aspects of English grammar. Although promising in principle, in practice it has been impossible to reach a definitive resolution to the controversy in this way. Both analyses appear to account for roughly the same range of data in English. (See Postal (1974), Bresnan (1976), Bach (3977) and Postal (1977).) A more practical way to distinguish between the two anaiyses is cross-linguistic. Do other languages exhibit an array of facts similar to that found in English? If so, can one of the approaches be generalized cross-Iinguistically while the other cannot? If it can be shown that one approach explains similar data in a broad range of languages, while the other is linked to peculiarities of English, the approach with wide cross-linguistic application is clearly to be preferred.

In the sections which follow we examine certain aspects of complementation in Imbabura Quechua (IQ). We show that data ana1ogous to (3) - (6) cannot be due to surface case marking. Rather, they would appear to be due to the derived constituency of the underlying complement subject. This suggests that a raising analysis is to be preferred for IQ. If raising is found to be the preferred analysis in all languages in which the facts distinguish between the two analyses, this would constitute strong evidence that SOR is the correct analysis whenever a range of facts like that seen in (1)-(6) occurs.

\section{Complementation in Imbabura Quechua}

IQ is spoken in Northern Ecuador and is a member of the Quechua A branch of the Quechua language family (cf. Parker 1969). As in most varieties of Quechua, complement clauses are generaily 
nominalized, and the complement clause is case marked in terms of its grammatical role in the matrix clause, as is illustrated in (9). $\begin{array}{llll}\text { Maria-ca } & \text { cri-n } & \text { Francisco cay-pi ca-j-ta } \\ \text { Maria-topic believe-3 } & \text { Francisco this-in be-pres Nom-acc }\end{array}$ 'Maria believes that Francisco is here.'

In addition to sentences like (9) in which the complement subject appears in nominative case, there is an additional pattern in which the complement subject is marked accusative:

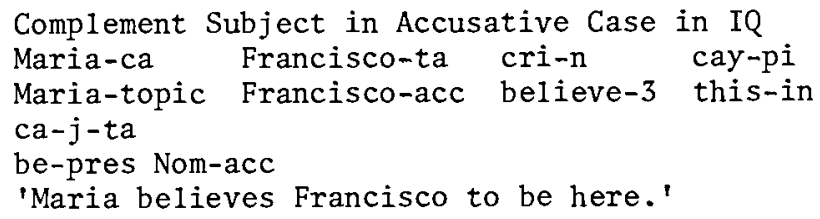

Sentences like (9) and (10) differ in much the same way that sentences (1) and (2) differ in English. The nominative underlying subject fails to undergo a variety of syntactic rules undergone by the accusative:

(11) Disjoint Reference in IQ

$\begin{array}{lll}\text { a. Jose } & \text { cri-n } & \begin{array}{c}{ }^{*} \text { pay-ta } \\ \text { pay-ta }\end{array} \text { cayna } \\ \text { Jose believe-3 } & \stackrel{\text { he-acc }}{\text { hesterday }} \text { yester }\end{array}$

shamu-shca-ta

come-past Nom-acc

'Jose ${ }_{i}$ believes him to have come yesterday.'

b. Jose ${ }_{i} \operatorname{cri}_{i}$ pay ${ }_{i j}$ cayna shamu-shca-ta Jose $e^{i}$ believe-3 he-nom yesterday come-past Nom-acc 'Jose believes that he ${ }_{i}$ came yesterday.'

(12) -11ataj Reflexivization in 1 id

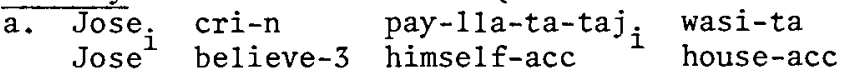

randi-shca-ta

buy-past Nom-acc

'Jose ${ }_{i}$ believes himself $f_{i}$ to have bought the house.'

b. *Jose ${ }_{i} \operatorname{cri-n}$ pay-11a-taj wasi-ta randi-shca-ta Jose $^{i}$ believe-3 himself-nom house-acc buy-past Nom-acc ('Jose ${ }_{i}$ believes that himself ${ }_{i}$ bought the house. ')

(13) Object Verb Agreement in IQ
a. Jose nuca-ta yacha-wa-n Maria-ta juya-j-ta

$\begin{array}{llll}\text { a. Jose nuca-ta } & \text { yacha-wa-n } & \text { Maria-ta juya-j-ta } \\ \text { Jose I-acc } & \text { know-1-3 } & \text { Maria-acc love-pres Nom-acc }\end{array}$

'Jose knows me to love Maria.'

b. *Jose yacha-wa-n ñuca Maria-ta juya-j-ta

Jose know-1-3 I-nom Maria-acc love-pres Nom-acc

('Jose knows me that I love Maria.") 
These "islandhood" facts would appear on first examination to be analyzable in the same way as the paralle1 English examples, either in terms of derived constituency (the raising analysis) or surface case (the NIC analysis). But, as will be seen shortly, this is not the case.

\section{Nominative Case and Islandhood}

It will be recalled that, according to NIC, it is surface case marking that determines islandhood. A noun phrase bearing nominative case is an island, while accusatives and obliques are not. We shall show in this section that it is not case marking in IQ, but, rather, subjecthood, which determines whether a noun phrase is an island. There is a class of verbs, the subjects of which receive accusative case. We shal1 show that despite having accusative case, these noun phrases pattern with the nominative complement subjects in (11)-(13) rather than with the accusatives.

The noun phrases in question are the subjects of two classes of verbs, -naya- desiderative experiencers, and lexical experiencers:

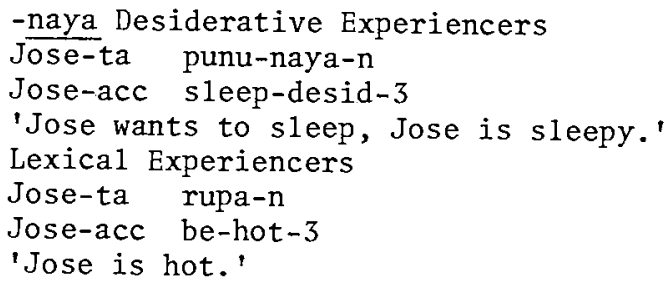

There are a variety of arguments that the accusative nominal Jose-ta is the subject in sentences 1 ike (14) and (15). One class of arguments is presented in Cole and Jake (1978). In addition, it can be shown that these noun phrases act like subjects with respect to the Opacity Condition (Chomsky 1978). See Cole and Hermon (1979) and Hermon (to appear) for details. We shall show now that the subjects of (14)-(15) behave like nominative noun phrases. These facts are compatible with the raising analysis, but not with an analysis in which islandhood is taken to reflect surface case marking.

\section{Disjoint Reference}

As predicted by the NIC analysis, nominative complement subjects fail to undergo disjoint reference, a rule of construal that marks anaphors as obligatorily non-coreferential with a potential antecedent. In (16) disjoint reference has not applied:

(16) Disjoint Reference Does Not Apply to Nominative Subject
Jose $i$ crin
he $[$ notin]
micu-ju-j-ta
Jose believes he[nom] eat-prog-pres Nom-acc
'Jose $i$ believes that he ${ }_{i, j}$ is eating.' 
In contrast, disjoint reference does apply to accusative underlying subjects in sentences like (16), as is shown in (11a) (repeated).

$$
\begin{aligned}
& \text { a. Disjoint Reference in IQ } \\
& \text { Jose }_{i} \text { cri-n } \text { *pay-ta }_{i} \text { cayna shamu-shca-ta } \\
& \text { Jose believe-3 he-tacc yesterday come-past Nom-acc } \\
& \text { 'Jose }{ }_{i} \text { believes him to have come yesterday.' }
\end{aligned}
$$

But NIC makes incorrect preditions with regard to accusative experiencers like those in (14) and (15). Accusative experiencers pattern with nominatives rather than with accusatives like those in (11a). This is illustrated in (17).

a. Disjoint Reference Does Not apply to Desiderative Experiencer Subject

$\begin{array}{lll}\text { Jose } & \text { cri-n } & \text { pay-ta } \\ \text { Jose } & \text { micu-naya-j-ta } \\ \text { believe-3 he-acc } & \text { eat-desid-pres Nom-acc }\end{array}$

'Jose ${ }_{i}$ believes that he ${ }_{i}$ wants to eat.'

b. Disjoint Reference Dós Not Apply to Lexical

Experiencer Subject

$$
\begin{aligned}
& \text { Jose cri-n } \text { pay-ta }_{i, j} \text { rupa-j-ta } \\
& \text { Jose }^{i} \text { believe-3 he-acc } \text { hot-pres Nom-acc }^{\text {'Jose }} \text { believes that he }_{i, j} \text { is hot.' }
\end{aligned}
$$

These facts constitute a straightforward counter-example to the claim that surface case marking determines islandhood. If that claim were correct, why would accusative experiencers be islands just like nominative noun phrases? But the raising analysis has no difficulty explaining these facts. Nominatives and accusative experiencers are "islands" because they remain constituents of the complement clause. In contrast, accusatives in sentences like (11a) are accessible to disjoint reference because they are matrix direct objects in derived structure.

An additional fact for which the NIC hypothesis provides no explanation, but which is an automatic consequence of the raising analysis, is the contrast between (11a) and (18).

(18) a. Disjoint Reference Applies with Desiderative Experiencer Jose-cabect which Precedes Matrix Verb

Jose-topic he-acc believe-z eat-desid-pres Nom-acc 'Jose believes him to want to eat.'

b. Disjoint Reference Applies with Lexical Experiencer Subject Which Precedes Matrix Verb

$$
\begin{aligned}
& \text { Jose-ca }_{i} \text { "pay-ta }_{i} \text { cri-n rupa-j-ta } \\
& \text { pay-taj } \\
& \text { Jose-topic he-acc believe-3 hot-pres Nom-acc } \\
& \text { 'Jose }{ }_{i} \text { believes him } \text { ho be hot.' }^{j} \text { to be }
\end{aligned}
$$


The raising analysis must claim that the accusative experiencer in (18) has undergone raising since the underlying complement subject appears to the left of the matrix verb. Thus, it would be predicted that disjoint reference would apply, and pay-ta would be marked as obligatorily non-coreferential to the matrix subject. The NIC analysis, in contrast, would predict that disjoint reference would apply in both (11a) and (18). It provides no explanation for the contrast.

\section{Validator Placement}

A second rule that groups nominative complement subjects and accusative experiencers together in contrast to other underlying accusative subjects (like (10)) is validator placement. Validators indicate the evidential status of the sentence. In general, the placement of validators is free. There is, however, an important restriction on their placement which is illustrated in (19) .

$$
\begin{aligned}
& \text { Validator Placement in IQ } \\
& \text { a. Juan-mi cri-n } \text { Maria Jose-ta ricu-shca-ta } \\
& \text { Juan-valid believe-3 Maria Jose-acc see-past Nom-acc } \\
& \text { 'It is Juan who believes that Maria saw Jose.' } \\
& \text { b. Juan cri-n-mi } \\
& \text { Juan believe-3-valid Maria Jose-ta ricu-shca-ta } \\
& \text { 'Juan believes [e.g., but doesn't know] that Maria saw } \\
& \text { Jose.' } \\
& \text { c. *Juan cri-n Maria-mi Jose-ta ricu-shca-ta } \\
& \text { Juan believe-3 Maria-valid Jose-acc see-past Nom-acc } \\
& \text { ('It's Maria who Juan believes saw Jose. ') } \\
& \text { d. *Juan cri-n Maria Jose-ta-mi ricu-shca-ta } \\
& \text { Juan believe-3 Maria Jose-acc-valid see-past Nom-acc } \\
& \text { ('It's Jose who Juan believes Maria saw.') } \\
& \text { e. *Juan cri-n Maria ricu-shca-mi } \\
& \text { Juan believe-3 Maria see-past Nom-valid Jose-ta } \\
& \text { ('Juan believes that Maria saw [e.g., not heard] Jose.') }
\end{aligned}
$$

As is shown in (19), the validator -mi 'first hand information" may not appear on constituents of the complement clause including nominative complement subjects. It may, however, be suffixed to accusative underlying subjects like that in (20).

(20) Accusative Underlying Complement Subjects Can Be Validated

$$
\begin{aligned}
& \text { a. Maria-ca Francisco-ta-mi yachan wasi-man } \\
& \text { Maria-topic Francisco-acc-valid knows house-to } \\
& \text { shamu-shca-ta }
\end{aligned}
$$

'It is Francisco whom Maria knows to have come home.' 


b. Maria yachan Francisco-ta-mi
Maria knows Francisco-acc-valid house-to
shamu-shca-ta
come-past Nom-acc

'It is Francisco whom Maria knows to have come home.'

The facts given so far are compatible with both the raising and the NIC analyses.

But the NIC analysis provides no explanation for the fact that the accusative experiencers in (21) cannot be validated.

(21) a. -naya Desiderative Experiencer Subjects

*Maria cushi cushi paypaj wawa-ta-mi

Maria happy happy her child-acc-valid

micu-naya-chun

eat-desid-subjunc Nom

('Maria is very happy that her child [e.g., not her husband] wants to eat. ")

b. Lexical Experiencer Subjects

*Maria cushi cushi Jose-ta-mi wasi-man

Maria happy happy Jose-acc-valid house-to

shamu-ngapaj muna-chun

come-subjunc Nom want-subjunc Nom

('Maria is very happy that Jose [e.g., not Francisco]

wants to come home. ')

This state of affairs is predictable on the basis of the raising analysis. The accusative experiencers in (21) are embedded beneath a matrix adjective (cushi 'happy') and, thus, cannot be raised into the matrix clause. This explains their islandhood. In contrast, the matrix predicate in (20) is a raising trigger (yacha- "know"). The underlying complement subject has been raised into the matrix clause, which explains the possibility of validation.

\section{Conclusions}

We have shown that in IQ the islandhood of certain complement subjects cannot be due to surface case marking, as Chomsky (1978) claimed in "On Binding, ${ }_{3}^{\prime}$ but, rather, seems to be due to derived constituent structure. As far as we know, there are no languages in which there is strong evidence favoring a surface case analysis. This suggests that the analysis proposed in Chomsky (1978) is based on a peculiarity of English, the fact that in English case marking and subjecthood show a high correlation. When such a correlation exists, it is hard to determine whether a particular syntactic phenominon (e.g., islandhood with respect to the rules in (3)-(6)) is due to nominative case or subjecthood. Our data suggest, however, that when nominative case and subjecthood are differentiated in a language, it will be found that islandhood is a property of complement subjects rather than nominative NPs. 


\section{NOTES}

*This paper is part of a larger project in which we seek to determine the extent to which the major claims of relationally based crosslinguistic syntax must be incorporated into the Extended Standard Theor: (EST). The purpose of this paper is to present evidence that Chomsky's (1978) proposals regarding the role of surface case in grammar appear to be based on peculiarities of English, and, thus, not to be generalizable cross-linguistically. For a fuller treatment of this question, see Cole and Hermon (1979).

We would like to thank Polly Jacobson, Chuck Kisseberth, Peter Landerman, Jerry Morgan, Henry Thompson, and David Weber for their comments on our claims. Thanks are also due to Carmen Chuquin for her insightful assistance in the study of Quechua syntax. This research was supported in part by grants from the Research Board of the University of Illinois and the National Science Foundation (grant number BNS 77-27159).

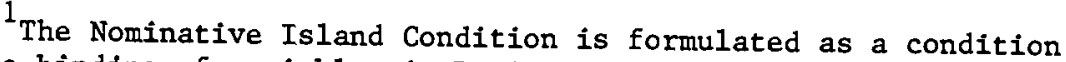
on the binding of variables in Logical Form. The condition acts in effect as a filter at the level of Logical Form, marking as 111-formed any derivation in which there is involvement between a nominative noun phrase and an element outside the clause containing the nominative. (This does not affect wh-movement for reasons we shall not discuss here. See Chomsky (1978) for details.)

2 It should also be noted that in the framework of EST, the rules in $(3)-(6)$ are not assumed to be clause bounded. In Cole and Hermon (1979) we examine the possibility of modifying the "On Binding" framework so as to include a rule of SOR and a Subject Island Condition. In that analysis, rules like those in (3)-(6) need not be clause bounded.

\footnotetext{
3 There are several additional arguments that we have omitted here for reasons of space. See Cole and Hermon (1979).
}

\section{REFERENCES}

Bach, Emmon. 1977. Review of P.M. Postal, On Raising: One Rule of English Grammar and Its Theoretical Implications, In William Bright, editor, Language, vol. 53, no. 3, pp. 621-54. Bresnan, Joan. 1976. "Nonarguments for Raising" In S.J. Keyser, editor, Linguistic Inquiry, vol. 7, no. 3, pp. 485-502.

Cole, Peter and G. Hermon. 1979. "Subject to Object Raising in an EST Framework: Evidence from Quechua" C.W. Kisseberth, B.B. Kachru, J.L. Morgan, editors, Studies in the Linguistic Sciences, University of Illinois: Urbana, Ill., vol. 9, no. 1. 
Hermon, Gabriella. 1979. "Relation-changing Rules in EST: Evidence from Inversion Construction," to appear.

Parker, Gary J. 1969. "Comparative Quechua Phonology and Grammar I: Ciassification." University of Hawaii, Working Papers in Linguistics, vo 1 . 1 , no. 1, pp 65-88.

Postal, Pau1 M. 1977. "About a "Nonargument" for Raising," in S.J. Keyser, Linguistic Inquiry, vo1. 8, no. 1, pp. 141-54. Postal, Paul M. 1974. On Raising: One Rule of English Grammar and Its Theoretical Implications, MIT Press: Cambridge, Massachusetts. 